\title{
Fifty Shades of Darkness: A Socio-Cognitive Information-Processing Framework Applied to Narcissism and Psychopathy
}

\author{
Barbara Lopes \\ University of Coimbra, Coimbra, Portugal
}

Hui Yu

De Montfort University, Leicester, United Kingdom

Catherine Bortolon

Université Grenoble Alpes, Grenoble, France

Rusi Jaspal

Nottingham Trent University, Nottingham, United Kingdom

\begin{abstract}
Existing trait-based and cognitive models of psychopathy and narcissism fail to provide a comprehensive framework that explains the continuum between sub-clinical and clinical presentations of those personalities and to predict associated maladaptive behavior in different social and cultural contexts. In this article, a socio-cognitive information-processing framework for narcissism and psychopathy (SCIPNP) is proposed to explain how psychopathic and narcissistic schemata influence the activation of psychological processes that interact with social and cultural contexts to display those personalities at a sub-clinical level. The proposed framework enables us to predict maladaptive behavior and to explain how sub-clinical narcissists and psychopaths develop personality disorders. The SCIPNP emphasizes the role of culture in shaping motives, appraisals, behavior and affect. Recommendations for future research are provided.
\end{abstract}

\section{Keywords}

Psychopathy; narcissism; processes; maladaptive behavior; culture.

\section{Introduction}

Narcissism is characterized by ideas of self-grandiosity and a personal sense of selfentitlement and psychopathy by callousness, viciousness and antisocial behavior, and both traits share a lack of empathy, disagreeableness, exploitative and manipulative characteristics (see Paulhus \& Williams, 2002). The traits of psychopathy and narcissism are increasingly categorized under the broader construct of "dark personalities" (see Furnham, Richards \& Paulhus, 2013 for a review). The prevalence of psychopathy and narcissism has been increasing (e.g., Babiak, Newman \& Hare, 2010; Stewart \& Bernhardt, 2010), especially in specific social, cultural and occupational contexts (e.g., Coid et al., 2009; Stinson et al., 2008).

There are two major paradigms in current research into clinical and sub-clinical presentations of narcissism and psychopathy: trait theories and cognitive theories. Trait theories, such as the trait circumplex model for the dark triad (Jones \& Paulhus, 2011) tend to describe these personalities as a list of traits, while cognitive approaches such as that of Beck, Davis and Freeman (2015a) often focus on the general information-processing model. These paradigms are characterized by limitations which are addressed in the framework proposed in this article.

In this article, the Socio-Cognitive Information-Processing Framework for Narcissism and Psychopathy (SCIPNP) is outlined to explain the social, cognitive and affective 
dimensions of sub-clinical narcissism and psychopathy. In the SCIPNP, affective and behavioral responses to internal or external stimuli are viewed as resulting from a dynamic interaction between bottom-up and top-down processes, which incorporate information from one's cultural background and personal experiences, as well as situational cues. Moreover, the SCIPNP explains how the cognitive schemata and specific appraisal processes underpin the observed similarities and differences between psychopathy and narcissism.

\section{Current personality theories}

\section{The Trait theory}

The Dark Personality Triad (Jones \& Paulhus, 2011) is comprised of three distinctive but related socially aversive sub-clinical personality traits: narcissism, psychopathy and machiavellianism (Paulhus \& Williams, 2002). All three dark triad personalities score low on agreeableness (Egan, 2009; Jakobwitz \& Egan, 2006; Paulhus, 2001; Paulhus \& Williams, 2002; Vernon, Villani, Vickers, \& Harris, 2008; Widiger \& Lynam, 1998). However, of the three dark personalities, psychopathy is associated with the least remorse and is most associated with callousness, impulsivity, thrill-seeking and criminal behavior, while narcissism is characterized by grandiosity, egocentrism and a sense of personal entitlement, and machiavellianism through strategic manipulation of others (Jones \& Paulhus, 2011).

The Dark Triad is considered to be a descriptive, rather than functional and processbased personality model (Collins et al., 2017; Mischel \& Schoda, 1995). It does not explain the mental processes that underpin the personalities or the causal factors underlying subclinical manifestations of psychopathy or narcissism; the role of social context in fluctuations in behavior and emotions (Mischel \& Schoda, 1995); or how mental processes and the social context interact to affect the display of behavior and emotion (i.e. individual processes-based constructs) and their variability over time (Collins et al., 2017).

The notion of a unified and trait-based dark triad personality can also be challenged. For instance, psychopathy and machiavellianism have been found to be negatively related to openness and conscientiousness whereas narcissism is not (Jacowbitz \& Egan, 2006; Paulhus $\&$ Williams, 2002). Moreover, psychopathy is much more associated with deviant behavior and predicts delinquency and criminality, while machiavellianism and narcissism do not (e.g., Buckels et al., 2014; Williams \& Paulhus, 2004). Therefore, the three dark personalities may actually be less unified than previously thought.

In light of studies that suggest that machiavellianism is conceptually separate from narcissism and is a sub-dimension of psychopathy (Giammarco \& Vernon, 2014; LeBreton, Binning \& Adorno, 2006; Persson, Kajonius \& Garcia, 2017) and in contrast to trait perspectives, we argue that machiavellianism is best conceptualized not as a distinct personality but as a selfish and manipulative strategy employed mainly by psychopaths to manipulate others (see Clempner, 2016) but that it can also be used to a lesser degree by narcissists (Malesza, 2020).

Furthermore, trait-based personality theories often postulate that personality is fixed and immutable. However, some research suggests that there are culturally specific aspects of these traits, and that they may vary across time, context and culture (e.g., Youli \& Chao, 2014).

\section{The Cognitive model of personality disorders}

In their cognitive model of personality, Beck, Davis and Freeman (2015a) suggest that personality traits can be conceptualized as an overt expression of the schemata that organize, select and synthesize incoming information. Thus, the activation of a specific schema will impact on the evaluation of the stimulus, the affective and motivation arousal, and on the selection and implementation of specific strategies. The authors suggest that the 
dysfunctional schemata found in personality disorders are the product of an interaction between the individual's genetic predisposition and exposure to (adverse) life events. Accordingly, they argue that "personality disorders represent an exaggeration of adaptive personality strategies" (p. 19) which become inflexible and overgeneralized as a consequence of challenging experiences. Although these strategies may be considered adaptive in evolutionary terms, their rigid nature renders them maladaptive in most contexts. The model suggests that personality disorders can also be understood as cognitive profiles - each personality disorder is characterized by a composite of beliefs, attitudes, affect, and behavior.

Nevertheless, this model does not describe the general narcissistic and psychopathic underlying personal needs/motives, cognitive appraisals and processes, or their behavioral and affective manifestations in sub-clinical populations. Moreover, it does not address how different processes are shaped and how they interact with social and cultural contexts, or their relationship with distinct personalities.

\section{Fifty shades of darkness: The sub-clinical and clinical presentations}

The SCIPNP is a framework oriented toward explaining sub-clinical presentations of narcissism and psychopathy while explaining why individuals with sub-clinical narcissism and psychopathy may gradually develop clinical presentations of narcissism and psychopathy.

Research has examined both quantitative (e.g., degree of severity) and qualitative (e.g., type of features, e.g., self-confidence for non-clinical vs. exhibitionism for clinical narcissism) continuum between sub-clinical and clinical presentations of narcissism and psychopathy (Aslinger et al., 2018; Edens et al., 2006; Vyas, 2015; Woodmass \& Connor, 2018). For example, individuals with both sub-clinical and clinical presentations of narcissism and psychopathy have been found to be egocentric, exploitative and to harm others, which can impede feelings of intimacy and relationship quality (Ali \& ChamorroPremuzic, 2010; Campbell \& Foster, 2002). They tend to behave in this way in order to obtain personal gratification (psychopathy) (Hare, 1999, 2003) or to safeguard self-esteem (narcissism) (Campbell, 1999).

Also, both sub-clinical and clinical presentations of narcissism and psychopathy have more or less adaptive facets and sub-types. For example, research has found four distinct facets of leadership/authority (more adaptive) vs. exhibitionism/exploitativeness (less adaptive) for narcissism (see Grijalva et al., 2015) and four distinct facets for psychopathy: affective/interpersonal (more adaptive) vs. lifestyle/antisocial (less adaptive) (Hare, 2003). A distinction has been made between two different types of narcissism: grandiose (high selfesteem, interpersonal dominance, tendency to over-estimate one's capabilities) vs. vulnerable narcissism (low self-esteem, insecure, hypervigilant of criticism) (Malesza \& Kaczmarek, 2018). Similarly, a distinction has been made between two types of psychopathy: primary (selfish, manipulative) vs. secondary psychopathy (antisocial, impulsive) (Skeem et al., 2003) that have distinct behavioral and affective outcomes (see Gray et al., 2019 - primary psychopathy is considered to be more adaptive whereas secondary psychopathy is considered to be less adaptive and to be related to impulsive and antisocial behavior).

Generally, it appears that sub-clinical psychopaths and narcissists present mostly adaptive, less severe and flexible features (in comparison to clinical psychopaths and narcissists who mostly exhibit rigid, severe, maladaptive and dysfunctional features) (Curry, Chesters \& Viding, 2011; Johnson, Hawes \& Straiton, 2014; Persson, 2013). However, this means that such individuals are less likely to achieve communal success and, as such, may experience difficulties in maintaining strong friendships, family bonds and romantic attachments (Campbell, 1999; Gervais et al., 2013). Nevertheless, it is likely that sub-clinical psychopaths and narcissists tend to exploit only their subordinates, while attempting to 
preserve their relationships with their close family and friends and with people in power for personal gain (Babiak et al., 2010; Braun, 2017). Conversely, clinical psychopathy and narcissism feature mostly severe, maladaptive and rigid features (e.g., persistent antisocial and criminal behavior; interpersonally harmful behaviors) (see Persson, 2013).

Not all individuals who exhibit sub-clinical narcissism and or psychopathy develop clinical narcissism and psychopathy [see Diagnostic Statistic Manual (DSM)-5 criteria, 2013]. Based on the proposed framework, we argue that (1) the readiness and inflexibility/rigidity of schemata availability and use; (2) the inability to adopt different schemata; (3) the activation and lack of self-regulation of malfunctioning "normal" processes e.g., biased cost-benefit analysis; (4) the lack of self-regulation in relation to the activation of narcissistic and psychopathic schemata and of consequent behavior and affect; and (5) specific brain changes/abnormalities that might sustain dysfunctional behavior, collectively, underpin the onset of clinical narcissism and psychopathy.

First, it is argued that some individuals develop narcissistic and or psychopathic schemata early on due to the influences of their culture, personal history and needs. These types of schema were once adaptive because they served a function and helped fulfill underlying motives/needs but become maladaptive and dysfunctional due to their rigidity and inflexibility (see Beck et al, 2015a), thereby leading to clinical presentations of narcissism and psychopathy.

Second, while clinical psychopaths and narcissists persistently activate their psychopathic and narcissistic schemata in any kind of situation, thus leading to an overgeneralization and lack of self-regulation in relation to psychopathic and narcissistic behavior, the sub-clinical individual will use the narcissistic and or psychopathic schemata only in specific social contexts in which they benefit from activating these schemata to pursue self-serving motives and needs.

Third, the maintenance of maladaptive appraisals in clinical narcissism and psychopathy is thought to be supported by an extremely distorted, rigid and consistent biased cost-benefit analysis and associated externalizing blame and empathy biases, which may prompt clinical psychopaths' transgressive and antisocial behavior, irrespective of the potential costs that this type of behavior entails for them and in particular for others (DeLisi et al., 2014).

Finally, it is proposed that the empathy deficits that are observed in clinical presentations of narcissism and psychopathy may be maintained by brain changes and abnormalities that are not generally observable in sub-clinical presentations, thus helping to sustain the dysfunctional behavior in clinical presentations (Hare, 1999; Hoppenbrouwers, Bulten \& Brazil, 2016; Ronningstam, 2017).

\section{The Socio-Cognitive Information-Processing Framework for Narcissism and Psychopathy (SCIPNP)}

The SCIPNP proposes that personality consists not only of individual traits but also of cognitive patterns, that is, overarching schemata and styles of appraisal. Consistent with a functionalist contextual approach (Biglan \& Hayes, 1996; Gifford \& Hayes, 1999), we argue that, in order to explain narcissistic and psychopathic personalities, it is necessary first to understand the inherent motivations underpinning affect and behavior in response to particular social and cultural cues (Gifford \& Hayes, 1999). From an evolutionary perspective, motives are conceptualized as drives that enable human beings to survive and to leave their genes behind (Gilbert, 2001) and are usually associated with personal needs (basic and socially driven) which must be satisfied (Dweck, 2017; Gilbert, 2001). They are also psychological drives that are culturally tailored and enable action in pursuit of a goal (Dweck, 2017). Hence, personalities can be thought of as the individual's drive to satisfy culturally 
specific needs and motives through personal interactions, which subsequently become part of the individual's personality schemata (see Dweck, 2017).

The SCIPNP also takes an information-processing approach, by drawing on cognitive theories of human behavior, evolutionary theories of psychopathology that focus on representations of social mentalities (see Gilbert, 2001), and social learning theory (Bandura, 1977), and proposes a stage-based framework (Beck et al., 2015ab) to understand narcissistic and psychopathic personalities' cognitive, affective and behavioral presentations. In contrast to Beck et al.'s (2015a) model, the SCIPNP emphasizes the role of culture in shaping narcissistic and psychopathic mental representations of needs/motivations and their contextdependent and schemata-driven appraisals at a sub-clinical level.

The following cognitive stages are proposed: Appraisal of the Antecedent, Organization of Response (Affect and Behavior domains), and the Appraisal of the Consequences (see Figure 1). These cognitive stages are sequential, with each stage influencing the next during decision-making and action-taking. Moreover, there are appraisal processes (and affective, behavioral and socio-cultural processes, such as ideological indoctrination, enculturation and cultural assimilation) in each cognitive stage that operationalize the display of both narcissistic and psychopathic behavior and affect (see Figure 1).

*Insert Figure 1*

\section{Cognitive Schemata}

A cognitive schema is conceptualized as a pattern of thought that organizes and categorizes information and the relationships between them (see for example, Young, 1999). It is composed of beliefs or cognitions, values, and appraisals related to oneself, others and the social environment. The beliefs or cognitions and appraisals that form part of a particular schema are thought to be socially constructed and, as such, have moral and emotional meanings attached to them which vary cross-culturally.

According to the SCIPNP, cognitive schemata are at the heart of information-processing, decision-making, behavior and subjective feelings. Most schemata have evolutionary and social roots and self-serving and self-protecting functions. For example, when competing for self-survival, maintaining self-superiority and taking revenge against others may be adaptive and are common patterns observed in both narcissists and psychopaths (Campbell \& Miller, 2012; Nathanson, 2008). Consequently, narcissists' and psychopaths' ways of thinking are not fundamentally different from those of the general population. Psychopathic and narcissistic schemata are thought to be adaptive in some situations because they help fulfill underlying needs and the pursuing of personal motives and goals according to specific cultural norms and values and the social context (McCain \& Campbell, 2018). However, they become maladaptive when the person is unable to deactivate those types of schema and associated malfunctioning processes. Depending on the type of schema that is activated, some appraisal processes may be absent at a given time and thus the behavior, cognitions and affect that are displayed may be a different subset of the common patterns. Appraisals, behavior and affect commonly observed in psychopathy and narcissism are summarized in Figure 2.

The most common schemata of psychopathic thinking include beliefs of the acceptability and entitlement to harm others for self-benefit; beliefs about the positivity of bold behavior (e.g., "Fortune favors the bold"); of the superiority of the individual's needs over morals and rules (e.g., "I am entitled to have fun even if it is illegal and breaks the rules"); non-remorseful beliefs (e.g., "I have no remorse after hurting others"); defiant beliefs against the authority ("The police does not deter me from doing what I want") and impulsivity/disinhibition ("I can do whatever I want how I want”) (Hare, 1999, 2003). 
These social predatory strategies must have been successfully implemented by our ancestors in the long evolutionary path to ensure our existence in the absence of cooperation (Dawkins \& Krebs, 1978). Therefore, self-serving at others' expense and prioritizing individual needs are long-standing. Even some of the perpetrators of the most horrific crimes (such as the Holocaust) have not been considered to be clinical psychopaths (Greiner \& Nunno, 1994). Psychopathic behavior may be enacted so that the individual can fulfill particular goals and associated underlying motives/needs that are ideologically indoctrinated (e.g., Nazi ideology) and under specific conditions, such as moving up the ranks or being commended by others. Hence, it seems that psychopathic mindsets still serve an adaptive role in some contexts, such as the workplace. For example, a high prevalence of psychopathic tendencies has been observed in senior management and among company chief executive officers (CEOs) (e.g., Babiak, Neumann \& Hare, 2010; Boddy, 2017; see also Landay, Harms \& Credé, 2019 for a meta-analysis). This research suggests that psychopathy is associated with power, high social rank and "success" - in Western cultures at least.

Although psychopathy may be characteristic of powerful individuals and serves the purpose of obtaining success and power by favoring selfish interests at the expense of others, this behavior is likely to vary in accordance with social context. For instance, a CEO may exhibit psychopathic behaviors in the workplace but not when interacting with his children in the family home. Thus, the deactivation of the psychopathic schemata is likely to occur in domains in which they do not serve an adaptive function. Therefore, there may be a degree of flexibility and of self-regulation of psychopathic schemata and behavior at the sub-clinical level (see Vyas, 2015).

Narcissism, on the other hand, is characterized by self-grandiose views and the distorted belief that one is essentially superior to others, which can provide feelings of self-satisfaction (Campbell \& Miller, 2012). This personality too has evolutionary and social roots. Human societies have long evolved into intricate hierarchies that determine the individual's worth, rank, status and role he/she plays and, as such, individuals have to compete with each other for resources and status, and defeat in social situations leads to shame and low social status and rank (see Gilbert, 2001). Hence, narcissism may be an evolutionary strategy that serves the purpose of adapting to challenging and competitive social contexts, promoting selfsurvival and personal success in hierarchical and status-based relationships.

In modern Western, industrialized societies, in which individualism is the dominant cultural orientation and interpersonal competitiveness is a key tenet of this cultural orientation, it is easy to see why narcissism might still perform an adaptive function. In particular, there is also an observed correlation between narcissism and success in leadership roles (Braun, 2017; Grijalva \& Newman, 2015).

Although some narcissists never develop psychopathic features, some do (Miller, Dir, Gentile, Wilson, Pryor \& Campbell, 2010). This may occur when individuals with narcissistic tendencies also possess psychopathic schemata, such as impulsive, antisocial and violent traits. The psychopathic schemata are sometimes also present in a narcissistic individual (see Kernberg \& Caligor, 2005; Ronningstam, 2005). Thus, there are clinical cases of narcissists and psychopaths who simultaneously exhibit characteristics of both narcissism and psychopathy, illustrating the continuum between the two (see Ronningstam, 2005).

\section{How are narcissistic and psychopathic schemata developed?}

It is likely that cognitive schemata are long-standing and developed on the basis of early childhood experiences, including parent-child interactions, which contribute to mental representations of the self and others and the relationships between them.

Clinical psychologists emphasize the importance of childhood experiences in prompting the development of psychological disorders, including the development of personality 
disorders (see Beck et al., 2015ab). For example, severe childhood traumatic experiences of abuse and neglect have been associated with the more severe facets of adult psychopathy (antisocial behavior, criminality) (Craparo, Schimmenti \& Caretti, 2013; Piquero et al., 2012). It is argued that the antisocial/impulsive facet of psychopathy that is characteristic of secondary psychopathy (see Skeem et al., 2003) reflects a detachment of emotions which can result from negative childhood experiences where the child learns to desensitize pain. The child thus develops working mental models of relationships based on their negative interactions with a caregiver (e.g., mother) that persist into adulthood and that focus on potential threat from others and insecure attachments. These mental models in adult psychopaths lead to ineffective and dysfunctional behavioral strategies (e.g., displaying excessive anger to elicit response from others) and to frustration to reward and non-response to punishment (Benning et al., 2003).

Consistent with attachment theory (see Bowlby, 1944), several studies have found positive associations between psychopathic traits and attachment insecurity in adults (Blanchard \& Lyons, 2016; Christian, Sellbom \& Wilkinson, 2017; Craig, Gray \& Snowden, 2013). In particular, most studies reveal an association between the impulsive/irresponsible component of psychopathy and attachment avoidance (dismissive attachment style) and attachment anxiety (preoccupied attachment style) (Christian, Sellbom \& Wilkinson, 2017; Craig, Gray \& Snowden, 2013).

Concerning narcissism, clinical theorists have often argued that adult narcissism can result from extreme forms of dysfunctional parenting. On the one hand, both Kernberg (1975) and Kohut (1977) have argued that narcissism is the product of cold, indifferent, rejecting or harsh parenting (e.g., authoritarian) that is inadequate in meeting the needs of the child, which in turn leads the child to fulfill those needs (e.g., need for recognition) in adulthood. The inadequate and insensitive parenting that some narcissists receive during childhood is thought to be associated with the development of the vulnerable type of adult narcissism that is characterized by low self-esteem and feelings of inferiority that are then "disguised" by attempts to show a grandiose "façade" (Kohut, 1977). Conversely, Millon (1981) proposed that parenting that is over-indulgent and characterized by parents putting their children on a pedestal can lead them to develop a grandiose type of narcissism.

It is argued that parents that over-indulge their children are then contributing to the formation of self-schemata in children which reflect their internalization of their parents' views of them being "special" (Millon, 1981). To maintain these grandiose schemata, strategies are developed that include exhibitionism and the pursuit of activities that have the sole purpose of inflating the self in the social environment (see McCain \& Campbell, 2018).

Empirical studies have examined the impact of childhood experiences and insecure attachment styles in developing adult narcissism. For example, some studies have found that overindulgent parenting (e.g., warmth and admiration) was linked especially to the grandiose type of narcissism in adults (e.g., Brummelman et al., 2015; Horton, Bleau \& Drewecki, 2006). Other studies have found that cold and rejecting parenting (e.g., lack of warmth) is linked especially to the vulnerable type of narcissism (Otway \& Vignoles, 2006; Smowleska $\&$ Dion, 2005). Moreover, parenting characterized by lack of supervision, psychological control and other types of inadequate parenting (i.e. more permissive and or more authoritarian, harsh discipline) are also related to adult narcissism (Cater, Zeigler-Hill \& Vonk, 2011; Horton et al., 2006; Wink, 1991).

Children learn through interactions with parents and peers, internalizing views of themselves and others that subsequently guide their behavior in later life. Moreover, insecure attachment styles developed in childhood influence and confirm adult narcissistic and psychopathic patterns of thought and action. For example, disorganized and preoccupied attachment styles due to childhood experiences of parental rejection and/or abuse are 
commonly associated with adult narcissistic/psychopathic aggression and heightened displays of negative affect (Craparo et al., 2013). Therefore, aggressive behavior serves to confirm one's views of others as threatening and indicates difficulties in self-regulation that are present in both adult narcissism and psychopathy (Ronningstam, 2017; Schimmenti et al., 2014). Conversely, avoidant/dismissive attachments developed in childhood serve to confirm grandiose views of oneself in adulthood since one develops an over-reliance on oneself, which confirms the view that one is special (Brennan \& Shaver, 1998; Craig, Gray \& Snowden, 2013). Experiences of abuse are particularly problematic, since both adult psychopaths and narcissists who suffer abuse during childhood and consequently have insecure attachment styles, experience difficulties in emotional, behavioral and cognitive selfregulation (see Schimmenti et al., 2014).

\section{The influence of culture in shaping adult narcissism and psychopathy}

Culture plays an important role in determining how an individual functions in a particular society by introducing values, norms and rules that guide cognition, affect and behavior. Cultural indoctrination uses socialization and enculturation and assimilation processes that teach culturally specific values/beliefs and needs and impose rules and behaviors that are socially expected within a particular culture. Hence, socialization of cultural values occurs early on, beginning within the family environment and in parental rearing practices and then later on are reinforced in the external environment (e.g., at school). According to social learning theory (see Bandura, 1977) children learn from very early on through observation and interaction with significant others the specific cultural values and norms to be followed. These values, beliefs and norms are internalized and, as such, define the child's needs/motives/goals and associated beliefs about themselves, others and the social world, guiding both their behavior and display of affect. For example, Chinese culture is based on Confucian values, and children are socialized and indoctrinated early on by their parents and in schools to respect elders, be obedient and obey authority. Confucian values also tend to celebrate group-orientation and assimilation within the group and co-operation. Therefore, children are encouraged to pursue collectivistic goals and to elaborate on their own inadequacies relative to other children in an effort to "blend in" or assimilate with others (Yu, 1996). Those beliefs also persist well into adulthood and shape adult life decisions and underlying motives and needs, such as marriage (Chen, 2006).

As a result of these socialization processes, people in Western and Eastern cultures tend to differ in the level of importance that they append to distinctiveness, with Westerners generally valuing individual distinctiveness vis-à-vis conformity which conversely is more valued by those in Eastern cultures (Triandis, 1989; Vignoles, Chryssochoou \& Breakwell, 2000). In support of culturally specific socialization processes, several studies have examined parenting styles in Eastern and Western cultures, as well as cultural differences within some ethnic groups (see Markus \& Kitayama, 1991). It is generally argued that Chinese parents are more authoritarian, perceive their children as being dependent on the family, and as having group responsibilities, thus promoting assimilation and interdependence (Peterson et al., 2003). In contrast, North American parents are reportedly less authoritarian and tend to praise children more often, focusing on attributes and behavior that differentiate their children from others, thereby promoting individual distinctiveness (Peterson et al., 2003).

There are thus likely to be cultural differences in the motives/needs and appraisals of both narcissistic and psychopathic individuals. For example, in Chinese culture filial piety is important, so the need of recognition from significant others may be displayed in a collective sense by Chinese narcissists (Gries, Sanders, Stroup \& Cai, 2015), whereas individualistic cultures that over-praise children and over-indulge them in schools and within families may 
later lead to a more agentic type of narcissism characterized by grandiose self-displays of superiority to satisfy distinctiveness (McCain \& Campbell, 2018).

In addition, studies show that, in collectivistic cultures, violence and anti-social behavior, which are characteristic of antisocial personality disorder (ASPD), are less observable and the prevalence of ASPD is lower than in individualistic cultures (see Compton et al., 2005- rates of ASPD between $0.10-0.20 \%$ in Taiwan vs. $1.49 \%$ to $5.66 \%$ in United States of America). Furthermore, Cooke (1996) and Gilbert (2005) argue that culturally specific socialization processes are important in explaining those differences. Individualistic cultures tend to allow displays of aggression more than collectivistic cultures (see Ekblad, 1990). Also, in contrast to collectivistic cultures, individualistic cultures seem to propagate the idea that compassion in certain contexts (e.g., the workplace) is a sign of weakness and thus is not conducive to individual gain and success in highly competitive environments (Gilbert, 2005). Therefore, individuals are socialized from early on to think that being compassionate is a weakness and that showing aggression and cruelty may be morally acceptable, especially if this leads to personal gain and success in competition, which are then characteristic of psychopathic leaders in the Western workplace (see Body, 2017).

In sum, it is argued that Western societies and/or any other societies that assimilate the individualistic neo-liberal cultural ideology of the survival of the fittest and self-made man will indoctrinate their citizens into the idea that using cut-throat and cruel tactics may be morally acceptable in certain contexts (e.g., competitive workplaces) and should be used to attain success and power and to move up in the social hierarchy (Gilbert, 2005; Pendergast, 2000). Moreover, Western societies also tend to promote narcissistic tendencies and to overpraise individuals indiscriminately e.g., Western celebrity adulation and mimicry display of narcissism and the Western parental over-praise and gratification of children (Gray, 2014). Therefore, those cultural tenets of individualistic Western societies might promote and shape the formation of sub-clinical psychopathic and narcissistic schemata in particular individuals. Thus, it is likely that, once activated, these schemata will help individuals achieve specific goals, e.g., being successful in the workplace, in the short term in specific contexts. Also, because individualistic Western cultures tend to accept and promote displays of egocentrism, manipulation, deceit and exploitation of others for self-benefit (see Gilbert, 2005; McCain \& Campbell, 2018), one might assume that it is adaptive to develop sub-clinical narcissism and psychopathy to survive and cope with challenges that occur in specific contexts within individualistic Western cultures. However, this does not mean that those individuals will develop clinical narcissism or psychopathy. Instead, this only means that "non-clinical" individuals can develop sub-clinical narcissism and psychopathy because both serve a purpose (e.g., being useful in competitive contexts) and are thus promoted in certain cultures and contexts.

\section{Appraisal of the Antecedent}

\section{*Insert Figure 2*}

Activation of schemata in this stage can be rather automatic, particularly if the set of schemata is the most readily available one, irrespective of the social context, or it can be a conscious activation (Beck et al., 2015ab). In this early stage of information-processing, the individual retrieves relevant past information from his/her database of past memories of similar events and of semantic knowledge and then applies them to the current situation.

The active schema may lead to biased and/or selective attention to particular aspects of the situation which are consistent with the schema's representation of the self, others and the world and the relationships between them. For example, if an individual has activated narcissistic and or psychopathic schemata, which include the belief "Other people can be exploited", then the individual may pay selective attention to people who appear to be easy to 
exploit and to manipulate (Book, Costello \& Camilleri, 2013). The active schemata may also lead people to make biased attributions to others which guide his/her behavior (e.g., "He/she looks old, so he/she must be weak"). Conversely, the individual will downplay or ignore other information which is inconsistent with these schemata. Furthermore, the activated schemata are likely to influence the ways in which the individual evaluates whether a situation is agreeable or threatening. This perception depends on the underlying motive that is guiding the individual's behavior toward a specific person in any given situation (e.g., to befriend the person to appear more popular by association vs. to compete with the person for high status).

The individual's activated narcissistic and or psychopathic schemata may also lead to biased empathy, that is, the tendency to ignore or downplay the pain of others while paying biased attention to his/her own feelings (see Farah, Amorim \& Chamorro-Premuzic, 2009; Hepper, Hart \& Sedikides, 2012). Moreover, a narcissistic or psychopathic individual may recall biased memories. For example, he/she may recall specifically his/her past successes in exploiting others without thinking about the pain he/she provoked in others (see Ritchie et al., 2015).

Socio-cultural processes may be activated in this stage thus influencing the biased recollection of memories that are culturally relevant and leading to biased attention processes in the situation (Aaker \& Schmitt, 2001). For example, when exposed to individualistic cultures that value particular exterior signs of status (e.g., a specific luxurious brand) and when appraising the situation in individualistic cultures, individuals from collectivistic cultures may assimilate this specific value and themselves seek signs of status in others with the intent to culturally "blend" in (Aaker \& Schmitt, 2001).

There is broad empirical support for the appraisal processes associated with psychopathic and narcissistic schemata outlined in Figure 1. For example, the Response Modulation Hypothesis for psychopathy (Newman \& Baskin-Sommers, 2011) postulates that abnormalities in both fear and inhibition in psychopathy are due to the presence of an "attention bottleneck" in this personality profile which "interferes with the processing of information that is congruent with a current goal rather than limitations in later stages of selection" (p.427). Similarly, in the SCIPNP, biased attention processes in psychopathy are said to lead to rigid behaviors in pursuit of a specific goal.

\section{Organization of Responses (Affect and Behavior domains)}

Having appraised the social context, the individual will append affective meaning to it. The activated schemata play the most important role in determining the individual's affective and behavioral responses to a situation. Schemata and the consequent display of affect and behavior are heavily influenced by socio-cultural processes. For example, a study has found that Chinese and other collectivistic cultures value low arousal emotions in contrast to Western cultures that value high arousal emotions, such as anger, and thus they avoid displaying high arousal emotions whereas in Western cultures, the display of those emotions is more common (Nangeyon, 2016). Moreover, collectivistic cultures, such as, the Korean culture tend to show less self-expression in public compared to North Americans (Park, 1998). This may be tied to the need/motivation in North American culture relative to East Asian cultures to express themselves as a way to differentiate themselves from others and also to maintain self-esteem and self-regard (Aaker \& Schmitt, 2001). Therefore, it is likely that behavioral and affective expressions of sub-clinical narcissists and psychopaths in Western cultures differ from those from Eastern cultures.

Individuals who activate narcissistic/psychopathic schemata in socially threatening situations (e.g., when publicly criticized by others) will most likely display intensified negative affect because they feel personally threatened (e.g., Durand, 2016; Falkenbach et al., 
2013; Geukes et al., 2017; Hare, 2003). This perception of threat may be attributed to the individual's persistent competitive and survival thinking that may be more prominent in Western individualistic cultures (Gebauer et al., 2012). For instance, when an individual has to compete with someone else for a job but fails, instead of accepting that only one out of a number people can actually get the post, he/she may feel personally threatened and, thus, intensely angry and ashamed.

The narcissistic and psychopathic schemata may also lead to difficulties in regulating negative affect and to disinhibition in behavior (Gray, Weidacker \& Snowden, 2019). For example, it has been reported that offenders with high levels of psychopathy exhibited a higher cardiovascular response when they processed negative, rather than positive information, in comparison to those with low levels of psychopathy (Casey, Rogers, Burns \& Yiend, 2017).

Psychopaths and narcissists may also use maladaptive emotional regulation strategies, such as excessive anger rumination (i.e. focusing on anger-related episodes and thoughts, see Sukhodolsky et al., 2001), which in turn can aggravate feelings of anger in the long term given its association with aggressive behaviors as coping responses (Bushman, 2002, Bushman et al., 2001). Indeed, anger rumination mediates the effect of narcissism on relational aggression, suggesting that narcissism leads to relational aggression only when anger rumination is also present (Ghim, Choi, Lim \& Lim, 2015).

Psychopathic and narcissistic people also exhibit biased empathy (see Farah et al., 2009; Ronningstam, 2017), that is, they tend to ignore or downplay the emotions that others feel (especially negative emotions, e.g., pain) and instead only pay attention to their own emotions. For example, narcissists experience difficulty in recognizing the emotions of others, exhibit low distress tolerance (Baskin-Sommers et al., 2014; Farah et al., 2009) and experience difficulties in emotional regulation (Schulze et al., 2013).

Avoidance of negative affect such as shame might be also utilized by people with narcissistic and psychopathic tendencies. For example, if the individual has activated narcissistic schemata including the belief "I am superior to others, so other people should treat me in a special way", he/she might avoid situations in which other people do not treat $\mathrm{him} / \mathrm{her}$ in a special way or make him/her feel inferior to others. This strategy is intended to downplay negative affect. Indeed, narcissists avoid situations that contradict their sense of self-worth in order to protect their own implicit self-esteem (e.g., Oltmanns \& Balsis, 2011). Similarly, if the individual has activated narcissistic and/or psychopathic schemata that include beliefs such as "I don't have any weaknesses", he/she might exhibit avoidant behaviors, e.g., alcohol and drug overuse in order to escape from intolerable affects and a threatened self-image (Beck et al., 2015a; Kealy, Ogrodniczuk, Rice \& Oliffe, 2017).

Moreover, people with narcissistic or psychopathic tendencies may feel entitled to display negative emotions, such as anger, and refuse to down regulate those negative emotions because they feel that other people in the situation are responsible for their own negative emotions (Ellis, Schroder, Patrick \& Moser, 2017; Morrison \& Gilbert, 2001). Consequently, they may exhibit disinhibited and or non-regulated affect in a situation of social threat, resulting in the display of immense anger toward other people (Durand, 2016). Moreover, reduced feelings of guilt make individuals with narcissistic and psychopathic tendencies less likely to make amends for their negative actions but more likely to engage in transgressive and vengeful behavior (Poless, Torstveit, Lugo, Andreassen \& Sütterlin, 2017; Prado, Treeby \& Crowe, 2016).

In contrast to this, narcissistic and psychopathic individuals with stable and consistent identities (characterized by self-esteem and devoid of insecurity) are less susceptible to such reactivity (e.g., Bateman, 1998) and, as such, are better adapted to challenging, socially threatening and competitive contexts. In this case, psychopaths, in particular, might be able to 
manipulate their explicit affect to achieve a specific motive. Thus, a psychopath might behave in a charming manner in order to win the trust of someone he/she actually intends to harm (see Hare, 1999).

Crucially, psychopathic and narcissistic individuals may also engage in calculated manipulative behavior, that is, machiavellianism. They may hide their "true" intentions and take strategic action to manipulate other people in line with their active schemata and underlying motives and associated goals. For example, under activated narcissistic schemata that include the belief that "Status is everything", narcissistic individuals may befriend popular people that they actually dislike with the underlying motive of boosting his/her selfsuperiority in relation to others (see Rose, 2007). In short, when narcissistic and psychopathic schemata are activated, individuals may feign (either successfully or not) calmness, agreeableness and positivity, in order to lure their target and manipulate them while retaining a positive public identity to display to others (see Porter, ten Brinke, Baker \& Wallace, 2011). This strategy is designed for self-benefit and can be adaptive in certain contexts (White, 2014).

Other behavioral strategies that are selfish and self-protective, e.g., avoiding negative states like feeling inferior to others; self-enhancing behaviors and exploiting; thrill-seeking and bold behaviors, deceiving; attacking others to protect and benefit the self; as well as taking revenge against others are thought to be present in non-clinical presentations of narcissism and psychopathy (see Beck et al., $2015 \mathrm{ab}$ ). While narcissists show reactive aggression, i.e., show aggression whenever they are provoked and particularly when their ego is being threatened, psychopaths do so not only when their ego is threatened but also when they are provoked physically (e.g., physical injury) (see Jones \& Paulhus, 2010). Moreover, in contrast to narcissists, psychopaths tend to exhibit also pro-active aggression, that is, unprovoked aggression, which is associated with the poor impulse control in psychopathy (Perenc \& Radochonski, 2014).

\section{Appraisal of the Consequences}

According to the SCIPNP, while pursuing a particular action, the individual will evaluate the consequences of his/her action. The individual with activated schemata will assess whether the behavior has either enabled him/her to react successfully to threat (which can be attributed to automatic/reactive self-protection) or has enabled him/her to meet his/her underlying motives/needs and conscious goals. The activated schemata will always lead to a schemata-driven and biased cost-benefit analysis of the consequences of one's behavior (see Clempner, 2016). For example, an individual may pay biased attention to and distort the meanings of his/her affective and physiological responses, i.e., a psychopathic individual may label sympathetic activation stimulated by the sight of discomfort in people being hurt (e.g., faster heartbeat) as pleasurable and exciting (Harenski, Thornton, Harenski, Decety \& Kiehl, 2012), also exhibiting biased empathy (e.g., Baskin-Sommers, et al., 2014; Farah et al., 2009).

The individual may also pay biased attention to aspects of the current situation, which lead to a distorted interpretation of the consequences of his/her behavior in general. Moreover, this can further lead to distorted interpretations of the consequences of his/her behavior to the self and others (e.g., "Others submitted to my showcase of power and of superiority, and I felt good." - narcissism and "I felt good putting down and harming other people and they seemed to fear me." - psychopathy), thereby reinforcing his/her original psychopathic and narcissistic logic and beliefs (e.g., "I am superior and others are inferior"narcissism and "I am entitled to harm others to feel good about myself" - psychopathy). 
The biased cost-benefit analysis is also linked to an externalizing blame bias, which is associated with psychopathic and narcissistic schemata (Bentall, Kinderman \& Kaney, 1994; Morrison \& Gilbert, 2001). An externalizing blame bias is a type of bias that is observed when people blame others for negative outcomes and consequences of their behavior instead of blaming themselves (Morrison \& Gilbert, 2001). Psychopathic and narcissistic individuals exhibit an externalizing blame bias because they are shame- and guilt-intolerant and have difficulties in regulating their emotions in socially threatening situations (Morrison \& Gilbert, 2001). This is observable in both clinical and non-clinical populations (Campbell \& Elison, 2005; Campbell \& Miller, 2012; Morrison \& Gilbert, 2001; Schalkwijck, Dekker, Peen \& Stems, 2016). Primary and secondary psychopathy (see Skeem et al., 2003) have a negative relationship with adaptive shame coping (e.g., submissive displays in a confrontation) and a positive relationship with externalizing blame (see Campbell \& Elison, 2005). Moreover, in their study of delinquent and non-delinquent adolescents, Schalkwijck, Dekker, Peen and Stems (2016) found a strong positive relationship between narcissism and externalizing blame for negative and shaming outcomes.

In short, it is argued that people with sub-clinical psychopathic and narcissistic tendencies generally conduct a biased cost-benefit analysis of the consequences of their behavior in the appraisal of consequences stage and exhibit an externalizing blame bias. The objective is to distance the cause of the negative consequences of their behavior from themselves onto others. As such, they will pay attention only to the benefits of their behavior to themselves and to their own emotions in response to the situation (i.e., biased empathy), as well as to stimuli supporting their self-serving narcissistic and psychopathic underlying motivations, needs and schemata.

\section{The Cognitive Loop: Reinforcement of the Schemata and Appraisals}

The loop of cognitive stages may unfold several times during information-processing and action-taking in the current situation and may also unfold in another similar social situation in dynamic and flexible ways. Moreover, context-dependent appraisals are consistent with the activated schemata and reinforce the particular dominant narcissistic and or psychopathic belief. For example, the individual who possesses the belief "I am entitled to exploit others for my self-benefit" in response to an opportunity to exploit others may: (1) re-evaluate the antecedent (e.g., "Is it a good opportunity to exploit?"); (2) evaluate his/her responses (e.g., predate, exploit, apologize, do nothing) (e.g., "I am so brilliant and others are inferior and stupid" when using exploitative strategies) and (3) evaluate the consequences of his/her responses (e.g., "Is my endeavor successful? Shall I follow up?"). When the consequences of the behavior fulfill the underlying needs and motives and associated goals in response to a specific situation (e.g., the psychopathic need to obtain pleasure and the associated motive of obtaining self-benefits through harming others), they will reinforce the underlying psychopathic cognitions and schemata, which may become dominant in the long- term. As such, the loop of cognitive stages that an individual experiences in a particular situation can be maintained in other analogous situations. Nevertheless, drawing from systems modeling (see Bramson, 2009), it is also argued that a dynamic system is not rigid. Hence, it is argued that, at a sub-clinical level, the SCIPNP system has a tipping point that occurs when it achieves a non-equilibrium state. For example, when costs severely outweigh the benefits, the system then shifts to a new state that is more adaptive- i.e. narcissistic and psychopathic schemata are de-activated and substituted by the activation of other schemata in response to a particular situation and as such, new behaviors are manifested. In conclusion, sub-clinical narcissistic and psychopathic behavior occurs in particular situations because it is adaptive in the short-term and in specific contexts, thereby enabling the individual to achieve specific goals and to satisfy his/her motives/needs. 


\section{Future research}

Future research should examine whether the appraisal processes described in the SCIPNP are present in sub-clinical presentations of psychopathy and narcissism and whether they underpin the continuum between sub-clinical and clinical presentations. A longitudinal research design would be advantageous. Research should also examine which social contexts are more likely to activate narcissistic and psychopathic schemata and how the appraisal processes described in this framework influence the display of both narcissistic and psychopathic adaptive and maladaptive behaviors. It is important to explore how the SCIPNP can be applied to understand diverse adaptive and maladaptive behaviors (e.g., trolling, Lopes \& Yu, 2017; and sexual risk-taking, Jaspal, Lopes, Wignall \& Bloxsom, 2021) in different social contexts and especially in under-researched cultural contexts, while testing SCIPNPbased practical interventions to reduce the incidence of maladaptive and antisocial behavior.

\section{Conclusion}

The proposed SCIPNP framework strives to provide a more comprehensive explanation of the continuum between clinical and sub-clinical presentations of psychopathy and narcissism than trait theory which has long dominated the field of personality research. In contrast to trait theories which do not generally explain the processing of information, the SCIPNP treats personality as a combination of cognition, affect and behavior which results from the dynamic interaction between the context (e.g., a situation in the workplace), culture and the cognitive schemata and appraisal processes that are activated at the present moment. The personalities' schemata serve as lenses through which one evaluates the situation, influencing affective and behavioral responses. In addition, the schemata also influence how one interprets the consequences of one's behavior and those consequences further reinforce the activation of the schemata under the next round of action in a perceived similar situation. The SCIPNP challenges the notion of fixed, consistent, universal traits by showing how human beings construct schemata or patterns of thinking that are situationally and culturally adaptive, flexible and advantageous.

\section{Acknowledgements}

We would like to thank Professor Shira Elqayam for her insightful ideas.

\section{Declaration of interest}

The authors have no interests to declare.

\section{References}

Aaker, J. \& Schmitt, B. (2001) Culture-dependent assimilation and differentiation of the Self: Preferences for consumption symbols in the United States and China. Journal of CrossCultural Psychology, 32(5), 561-576. https://doi.org/10.1177/0022022101032005003

Ali, F., \& Chamorro-Premuzic, T. (2010). The dark side of love and life satisfaction: Associations with intimate relationships, psychopathy and Machiavellianism. Personality and Individual Differences, 48(2), 228-233. https://doi.org/10.1016/j.paid.2009.10.016

American Psychiatric Association (APA) (2013) Diagnostic and Statistical Manual of Mental Disorders (5th Edition). Washington, D.C.: American Psychiatric Association Publications. https://doi.org/10.1176/appi.books.9780890425596 
Aslinger, E., Manuck, S., Pilkonis, P., Simms, L. \& Wright, A. (2018). Narcissistic or narcissistic? The evaluation of the latent structure of narcissistic personality disorder. Journal of Abnormal Psychology, 127(5), 496-502. https://doi.org/10.1037/abn0000363

Babiak, P., Neumann, S. C., Hare, D. R. (2010) Corporate psychopathy: Talking the walk. Behavioral Sciences \& Law, 28(2), 174-193. https://doi.org/10.1002/bsl.925

Bandura, A. (1977) Self-efficacy: Toward a unifying theory of behavioral change. Psychological Review, 84(2), 191-215. https://doi.org/10.1037/0033-295X.84.2.191

Baskin-Sommers, A., Krusemark, E., \& Ronningstam, E. (2014). Empathy in narcissistic personality disorder: From clinical and empirical perspectives. Personality Disorders: Theory, Research, and Treatment, 5(3), 323-333. https://doi.org/10.1037/per0000061

Bateman, A. W. (1998) Thick- and thin-skinned organisations and enactment in borderline and narcissistic disorders. International Journal of Psychoanalysis, 79(1), 13-25.

Blanchard, A., \& Lyons, M. (2016). Sex differences between primary and secondary psychopathy, parental bonding, and attachment style. Evolutionary Behavioral Sciences, 10(1), 56-63. https://doi.org/10.1037/ebs0000065

Beck, A. T., Davis, D. \& Freeman, D. (2015a) Theory of Personality Disorders (3rd Edition). New York, NY: Guilford Press.

Beck, A. T., Davis, D. D., \& Freeman, A. (Eds.). (2015b). Cognitive therapy of personality disorders. New York, NY: Guilford Publications.

Benning, S. D., Patrick, C. J., Hicks, B. M., Blonigen, D. M., \& Krueger, R. F. (2003). Factor structure of the Psychopathic Personality Inventory: Validity and implications for clinical assessment. Psychological Assessment, 15(3), 340-350. https://doi.org/10.1037/1040$\underline{3590.15 .3 .340}$

Bentall, R., Kinderman, P., \& Kaney, S. (1994). The self, attributional processes and abnormal beliefs: Towards a model of persecutory delusions. Behavior Research and Therapy, 32(3), 331-341. https://doi.org/10.1016/0005-7967(94)90131-7

Biglan, A., \& Hayes, S. C. (1996). Should the behavioral sciences become more pragmatic? The case for functional contextualism in research on human behavior. Applied and Preventive Psychology: Current Scientific Perspectives, 5(1), 47-57. https://doi.org/10.1016/S0962$\underline{1849(96) 80026-6}$

Blair, R., Jones, L., Clark, F. \& Smith, M. (2007) The psychopathic individual: a lack of responsiveness to distress cues? Psychophysiology, 34(2), 192-198. https://doi.org/10.1111/j.1469-8986.1997.tb02131.x

Body, R. C. (2017) Psychopathic leadership: A case study of a corporate psychopath CEO. Journal of Business Ethics, 145, 141-156. https://doi.org/10.1007/s10551-015-2908-6 
Book, A., Costello, K. \& Camilleri, J. (2013) Psychopathy and victim selection: The use of gait as a cue to vulnerability. Journal of Interpersonal Violence, 28(11), 2368-2383 https://doi.org/10.1177/0886260512475315

Bowlby, J. (1944). Forty-four juvenile thieves: Their character and home-life. International Journal of Psychoanalysis, 25, 19-52.

Bramson, A. (2009) Formal measures of dynamical properties: Tipping, robustness and path dependence. AAAI Fall Symposium: Complex Adaptive Systems and the Threshold effect.

Braun, S. (2017) Leader narcissism and outcomes in organizations: A review at multiple levels of analysis and implications for future research. Frontiers in Psychology, 8(773), 1-22. https://doi.org/10.3389/fpsyg.2017.00773

Brennan, K. A., \& Shaver, P. R. (1998). Attachment styles and personality disorders: Their connections to each other and to parental divorce, parental death, and perceptions of parental caregiving. Journal of Personality, 66(5), 835-878. https://doi.org/10.1111/1467-6494.00034

Brummelman, E., Thomaes, S., Nelemans, S.A., Orobio de Castro B. \& Bushman, B.J. (2014) My child is God's gift to humanity: Development and validation of the Parental Overvaluation Scale (POS). Journal of Personality and Social Psychology, 108(4), 665-679. https://doi.org/10.1037/pspp0000012

Buckels, E., Trapnell, P., \& Paulhus, D. (2014). Trolls just want to have fun. Personality and Individual Differences, 67, 97-102. https://doi.org/10.1016/j.paid.2014.01.016

Bushman, B. J. (2002) Does venting anger feed or extinguish the flame? Catharsis, rumination, distraction, anger, and aggressive responding. Personality and Social Psychology Bulletin, 28(6), 724-731. https://doi.org/10.1177/0146167202289002

Bushman, B. J., Baumeister, R. \& Phillips, M. C. (2001) Do people aggress to improve their mood? Catharsis beliefs, affect regulation, opportunity, and aggressive responding. Journal of Personality and Social Psychology, 81(1), 17-32. https://doi.org/10.1037/0022-3514.81.1.17

Campbell, W.K. (1999) Narcissism and romantic attraction. Journal Personality and Social Psychology, 77(6), 1254-1270. https://doi.org/10.1037/0022-3514.77.6.1254

Campbell, S.J. \& Elison, J. (2005) Shame coping styles and psychopathic personality traits. Journal of Personality Assessment, 84(1), 96-104. https://doi.org/10.1207/s15327752jpa8401 16

Campbell, W. K., \& Foster, C. A. (2002). Narcissism and commitment in romantic relationships: An investment model analysis. Personality and Social Psychology Bulletin, 28(4), 484-495. https://doi.org/10.1177/0146167202287006

Campbell, W. K., \& Miller, J. D. (2012). The handbook of narcissism and narcissistic personality disorder: Theoretical approaches, empirical findings, and treatments. Hoboken, N.J: John Wiley \& Sons. https://doi.org/10.1002/9781118093108 
Casey, H., Rogers, R. D., Burns, T., \& Yiend, J. (2013). Emotion regulation in psychopathy. Biological Psychology, 92(3), 541-548. https://doi.org/10.1016/j.biopsycho.2012.06.011

Cater, T. E., Zeigler-Hill, V., Vonk, J. (2011). Narcissism and recollections of early life experiences. Personality and Individual Differences, 51(8), 935-939. https://doi.org/10.1016/j.paid.2011.07.023

Chen, C. (2006). From filial piety to religious piety: Evangelical Christianity reconstructing Taiwanese immigrant families in the United States. International Migration Review, 40(3), 573-602. https://doi.org/10.1111/j.1747-7379.2006.00032.x

Christian, E., Sellbom, M., \& Wilkinson, R. B. (2017). Clarifying the associations between individual differences in general attachment styles and psychopathy. Personality Disorders: Theory, Research, and Treatment, 8(4), 329-339. https://doi.org/10.1037/per0000206

Clempner, B. J. (2016) A game theory model for manipulation-based Machiavellianism: moral and ethical behaviour. Journal of Artificial Societies and Social Simulation, 20(2) 1-16. https://doi.org/10.18564/jasss.3301

Coid, J., Yang, M., Ulrich, S., Roberts, A. \& Hare, R.D. (2009) Prevalence and correlates of psychopathic traits in the household population of Great Britain. International Journal of Law \& Psychiatry, 32(2), 65-73. https://doi.org/10.1016/j.ijlp.2009.01.002

Collins, D. M., Jackson, J. C., Walker, R. B., O'Connor, P. J. \& Gardiner, E. (2017) Integrating the context-appropriate balanced attention model and reinforcement sensitivity theory: Towards a domain-general personality process model. Psychological Bulletin, 143(1), 91-106. https://doi.org/10.1037/bul0000082

Compton, W.M., Conway, K.P., Stinson, F.S,. Colliver, J.D. \& Grant, B.F. (2005) Prevalence, correlates, and comorbidity of DSM-IV antisocial personality syndromes and alcohol and specific drug use disorders in the United States: Results from the national epidemiologic survey on alcohol and related conditions. Journal of Clinical Psychiatry, 66(6), 677-685. https://doi.org/10.4088/JCP.v66n0602

Cooke, D. (1996) Psychopathic personality in different cultures: What do we know? What do we need to find out? Journal of Personality Disorders, 10(1), 23-40. https://doi.org/10.1521/pedi.1996.10.1.23

Craig, R. L., Gray, N. S., \& Snowden, R. J. (2013). Recalled parental bonding, current attachment, and the triarchic conceptualisation of psychopathy. Personality and Individual Differences, 55(4), 345-350. https://doi.org/10.1016/j.paid.2013.03.012

Craparo, G., Schimmenti, A. \& Caretti, V. (2013). Traumatic experiences in childhood and psychopathy: a study on a sample of violent offenders from Italy. European Journal of Psychotraumatology, 4(1), 214-71. https://doi.org/10.3402/ejpt.v4i0.21471

Curry, O., Chesters, M. J., \& Viding, E. (2011). The psychopath's dilemma: The effects of psychopathic personality traits in one-shot games. Personality and Individual Differences, 50(6), 804-809. https://doi.org/10.1016/j.paid.2010.12.036 
Dargis, M., Newman, J. \& Koenigs, M. (2016). Clarifying the link between childhood abuse history and psychopathic traits in adult criminal offenders. Personality Disorders, 7(3), 221228. https://doi.org/10.1037/per0000147

Dawkins, R., \& Krebs, J. R. (1978). Animal signals: Information or manipulation. In J. R. Krebs \& N. B. Davies (Eds.), Behavioral ecology: An evolutionary approach (pp. 282-309). Oxford, England: Blackwell.

DeLisi, M., Angton, A., Vaughn, V. M., Trulson, R. C., Caudill, W. J. \& Beaver, K. (2014) Not my fault: Blame externalization is the psychopathic feature most associated with pathological delinquency among confined delinquents. International Journal of Offender Therapy and Comparative Criminology, 58(12), 1415-1430. https://doi.org/10.1177/0306624X13496543

Durand, G. (2016). A replication of "Using self-esteem to disaggregate psychopathy, narcissism, and aggression (2013)". Quantitative Methods Psychology, 12(2), 1-5. https://doi.org/10.20982/tqmp.12.2.r001

Dweck, C. S. (2017). From needs to goals and representations: Foundations for a unified theory of motivation, personality, and development. Psychological Review, 124(6), 689-719. https://doi.org/10.1037/rev0000082

Edens, J. F., Marcus, D. K., Lilienfield S. O. \& Poythress, N.G., Jr (2006) Psychopathic, not psychopath: taxometric evidence for the dimensional structure of psychopathy. Journal of Abnormal Psychology, 115(1), 131-144. https://doi.org/10.1037/0021-843X.115.1.131

Egan, V. (2009, July). The main predictors of aggression: Low A, low A, and low A? Paper presented at meeting of the International Society for the Study of Individual Differences, Evanston, Iillinois.

Ekblad, S. (1990) The children's behaviour questionnaire for completion by parents and teachers in a Chinese sample. Journal of Child Psychology \& Psychiatry, 31(5), 775-791. https://doi.org/10.1111/j.1469-7610.1990.tb00817.x

Ellis, D. E., Schroder, S. H., Patrick, C. \& Moser (2017) Emotional Reactivity and regulation in individuals with psychopathic traits: Evidence for a disconnect between neurophysiology and self-report. Psychophysiology, 54(10), 1574-1585. https://doi.org/10.1111/psyp.12903

Falkenbach, D. M., Howe, J. R., \& Falki, M. (2013). Using self-esteem to disaggregate psychopathy, narcissism, and aggression. Personality and Individual Differences, 54(7), 815820. https://doi.org/10.1016/j.paid.2012.12.017

Farah, A., Amorim, I. \& Chamorro-Prezumic, T. (2009) Empathy deficits and trait emotional intelligence in psychopathy and machiavellianism. Personality and Individual Differences, 47(7), 758-762. https://doi.org/10.1016/j.paid.2009.06.016

Furnham, A. \& Richards, S. \& Paulhus, D. (2013) The Dark Triad of Personality: A 10 Year Review. Social and Personality Psychology Compass, 7/3, 199-216. https://doi.org/10.1111/spc3.12018 
Gebauer, J. E., Sedikides, C., Verplanken, B., \& Maio, G. R. (2012). Communal narcissism. Journal of Personality and Social Psychology, 103(5), 854-878. https://doi.org/10.1037/a0029629

Gervais, M. M., Kline, M., Ludmer, M., George, R. \& Manson, J. H. (2013) The strategy of psychopathy: primary psychopathic traits predict defection on low-value relationships. Proceedings of the Royal Society B, 280, 20122773. https://doi.org/10.1098/rspb.2012.2773

Geukes, K., Nestler, S., Hutteman, R., Dufner, M., Küfner, A. C., Egloff, B., et al. (2017). Puffed-up but shaky selves: State self-esteem level and variability in narcissists. Journal of Personality and Social Psychology, 112(5), 769-786. https://doi.org/10.1037/pspp0000093

Giammarco A. E. \& Vernon, A.P. (2014) Vengeance and the Dark Triad: the role of empathy and perspective taking in trait forgivingness. Personality and Individual Differences, 67, 2327. https://doi.org/10.1016/j.paid.2014.02.010

Gibbon, S., Dugan C., Stoffers, J., Huband, N., Völlm B., Ferriter, M. \& Lieb, K. (2010) Psychological interventions for antisocial personality disorder. Cochrane Database Systematic Review, 6, CD007668. https://doi.org/10.1002/14651858.CD007668.pub2

Gifford, E.V. \& Hayes, S.C. (1999). Functional contextualism: A pragmatic philosophy for behavioral science. In W. O'Donohue \& R. Kitchener (Eds.), Handbook of behaviorism (pp. 285-327). San Diego: Academic Press. https://doi.org/10.1016/B978-012524190-8/50012-7

Gilbert, P. (2001). Evolutionary approaches to psychopathology: The role of natural defences. Australian New Zealand Journal of Psychiatry, 35(1), 17-27. https://doi.org/10.1046/j.14401614.2001.00856.x

Gilbert, P. (2005). Compassion and cruelty: A biopsychosocial approach. In P. Gilbert (Ed.), Compassion: Conceptualisations, research and use in psychotherapy (p. 9-74). Routledge. https://doi.org/10.4324/9780203003459

Ghim, S. C., Choi, D. H., Lim, J. J., \& Lim, S. M. (2015). The relationship between covert narcissism and relational aggression in adolescents: Mediating effects of internalized shame and anger rumination. International Journal of Information and Education Technology, 5(1), 21. https://doi.org/10.7763/IJIET.2015.V5.469

Gorman, C.J. (1998) Parenting attitudes and practices of immigrant Chinese mothers and adolescents. Family Relations, 47(1), 73-80. https://doi.org/10.2307/584853

Gray, P. (2014) Why is Narcissism Increasing Among Young Americans? Psychology today. [Accessed 13 $3^{\text {th }}$ March 2020: https://www.psychologytoday.com/us/blog/freedomlearn/201401/why-is-narcissism-increasing-among-young-americans]

Gray, N. S., Weidacker, K. \& Snowden, R. J. (2019) Psychopathy and impulsivity: The relationship between psychopathy to different aspects of UPPS-P impulsivity. Psychiatry Research, 272, 474-482. https://doi.org/10.1016/j.psychres.2018.12.155 
Greiner N. \& Nunno, V. J. (1994) Psychopaths at Nuremberg? A Rorschach analysis of the records of Nazi criminals. Journal of Clinical Psychology, 50(3), 415-429. https://doi.org/10.1002/1097-4679(199405)50:3<415::AID-JCLP2270500313>3.0.CO;2-M

Gries, P., Sanders, M., Stroup, D., \& Cai, H. (2015). Hollywood in China: How American popular culture shapes Chinese views of the 'Beautiful Imperialist,' an experimental analysis. The China Quarterly, 224, 1070-1082. https://doi.org/10.1017/S0305741015000831

Grijalva, E., \& Newman, D. A. (2015). Narcissism and counterproductive work behavior (CWB): Meta-analysis and consideration of collectivist culture, Big Five personality, and narcissism's facet structure. Applied Psychology, 64(1), 93-126. https://doi.org/10.1111/apps.12025

Hare, R. D. (1999). Without conscience: The disturbing world of the psychopaths among us. New York: Guilford.

Hare, R. D. (2003). The Hare Psychopathy Checklist - revised (2nd ed.). Toronto, ON:MultiHealth Systems.

Harenski, C.L., Thornton, D.M., Harenski, K. A., Decety, J. \& Kiehl, K. A. (2012) Increased frontotemporal activation during pain observation in sexual sadism: preliminary findings. $\begin{array}{lllll}\text { Archives of } & \text { General 283-299. }\end{array}$ https://doi.org/10.1001/archgenpsychiatry.2011.1566

Hepper, E. G., Hart, C. M., \& Sedikides, C. (2014). Moving Narcissus: Can narcissists be empathic? Personality and Social Psychology Bulletin, 40(9), 1079-1091. https://doi.org/10.1177/0146167214535812

Hoppenbrouwers, S. S., Bulten, B. H., \& Brazil, I. A. (2016). Parsing fear: A reassessment of the evidence for fear deficits in psychopathy. Psychological Bulletin, 142(6), 573-600. https://doi.org/10.1037/bul0000040

Horton, R. S., Bleau, G., \& Drwecki, B. (2006). Parenting Narcissus: What are the links between parenting and narcissism? Journal of Personality, 74(2), 345-376. https://doi.org/10.1111/j.1467-6494.2005.00378.x

Jakobwitz, S., \& Egan, V. (2006). The dark triad and normal personality traits. Personality and Individual Differences, 40(2), 331-339. https://doi.org/10.1016/j.paid.2005.07.006

Jaspal, R., Lopes, B., Wignall, L., \& Bloxsom, C. (2021). Predicting sexual risk behavior in British and European Union university students in the United Kingdom. American Journal of Sexuality Education. https://doi.org/10.1080/15546128.2020.1869129

Johnston, L., Hawes, D. J., \& Straiton, M. (2014). Psychopathic traits and social cooperation in the context of emotional feedback. Psychiatry, Psychology and Law, 21(5), 767-778. https://doi.org/10.1080/13218719.2014.893550

Jones, D. N. \& Paulhus, D. L. (2010) Different Provocations Trigger Aggression in Narcissists and Psychopaths. Social Psychological and Personality Science, 1(1), 12-18. https://doi.org/10.1177/1948550609347591 
Jones, D. N. \& Paulhus, D. L. (2011) Differentiating the Dark Triad within the interpersonal circumplex. In L.M. Horowitz \& S. Strack (eds.), Handbook of Interpersonal Psychology: Theory, Research, Assessment, and Therapeutic Interventions (pp.249-269). New York: Wiley \& Sons. https://doi.org/10.1002/9781118001868.ch15

Kealy, D., Ogrodniczuk, J. S., Rice, S. M., \& Oliffe, J. L. (2017). Pathological narcissism and maladaptive self-regulatory behaviours in a nationally representative sample of Canadian men. Psychiatry Research, 256, 156-161. https://doi.org/10.1016/j.psychres.2017.06.009

Kernberg, O. (1975). Borderline conditions and pathological narcissism. New York: Jason Aronson.

Kernberg, O. F., \& Caligor, E. (2005). A psychoanalytic theory of personality disorders. In M. F. Lenzenweger, \& J. Clarkin (Eds.), Major theories of personality disorder (pp. 114-156). New York: Guilford Press.

Kohut, H. (1977). The restoration of the self. New York, NY: International Universities Press.

Landay, K., Harms, P.D. \& Credé, M. (2019) Shall we serve the dark lords? A meta-analytical review of psychopathy and leadership. Journal of Applied Psychology, 104(1), 183-196. https://doi.org/10.1037/ap10000357

LeBreton, J., Binning, J., \& Adorno, A. (2006). Subclinical psychopaths. In J. C. Thomas \& D. Segal (Eds.), Comprehensive handbook of personality and psychopathology. Vol. 1: Personality and everyday functioning (pp. 388 - 411). Hoboken, NJ: Wiley.

Lopes, B. \& Yu, H. (2017) Who do you troll and why? An investigation into the relationship between the Dark Triad Personalities and online trolling behaviours towards popular and less popular Facebook profiles. Computers in Human Behaviour, 77, 69-76. https://doi.org/10.1016/j.chb.2017.08.036

Malesza, M. (2020) The effects of the Dark Triad traits in prisoner's dilemma game. Current Psychology, 39, 1055-1062. https://doi.org/10.1007/s12144-018-9823-9

Malesza, M. \& Kaczmarek, C. M. (2018) Grandiose narcissism versus vulnerable narcissism and impulsivity. Personality \& Individual Differences, 126, 61-65. https://doi.org/10.1016/j.paid.2018.01.021

Markus, H. \& Kitayama, S. (1991) Culture and self: Implications for cognition, emotion \& motivation. Psychological Review, 98(2), 224-253. https://doi.org/10.1037/0033$\underline{295 X .98 .2 .224}$

Martin, S. R., Cote, S., \& Woodruff, T. (2016). Echoes of our upbringing: How growing up wealthy or poor relates to narcissism, leader behavior, and leader effectiveness. Academy Management Journal, 59(6), 2157-2177. https://doi.org/10.5465/amj.2015.0680

McCain, J. L. \& Campbell, W. K. (2018) Narcissism and social media use: a meta-analytical review. Psychology of Popular Media Culture, 7(3), 308-317. https://doi.org/10.1037/ppm0000137 
Miller, J.D., Dir, A., Gentile, B., Wilson, L., Pryor, R. \& Campbell, L.W. (2010) Searching for a vulnerable dark triad: comparing factor 2 psychopathy, vulnerable narcissism and borderline personality disorder. Journal of Personality, 78(5), 1529-64. https://doi.org/10.1111/j.1467-6494.2010.00660.x

Millon, T. (1981). Disorders of personality: DSM III: Axis II. Chichester, UK: John Wiley.

Mischel, W. \& Schoda, Y. (1995) A Cognitive-Affective System Theory of Personality: Reconceptualizing Situations, Dispositions, Dynamics, and Invariance in Personality Structure. Psychological Review, 102(2), 246-268. https://doi.org/10.1037/0033295X.102.2.246

Morrison, D., \& Gilbert, P. (2001). Social rank, shame and anger in primary and secondary psychopaths. The Journal of Forensic Psychiatry, 12(2), 330-356. https://doi.org/10.1080/09585180110056867

Nangyeon, L. (2016) Cultural differences in emotion: differences in emotional arousal level between East and West. Integrative Medicine Research, 5(2), 105-109. https://doi.org/10.1016/j.imr.2016.03.004

Nathanson, C. (2008) Exploring the Dynamics of Revenge. Unpublished $\mathrm{PhD}$ dissertation. University of British Colombia, Vancouver, Canada. https://open.library.ubc.ca/cIRcle/collections/ubctheses/24/items/1.0066779

Newman, J. P., \& Baskin-Sommers, A. (2011). Early selective attention abnormalities in psychopathy: Implications for self-regulation. In M. Posner (Ed.), Cognitive neuroscience of attention (pp. 421-440). New York, NY: Guilford Press

Olsen, K. J., \& Stekelberg, J. (2016). CEO narcissism and corporate tax sheltering. Journal of American Taxation Association, 38(1), 1-22. https://doi.org/10.2308/atax-51251

Oltmanns, T. F., \& Balsis, S. (2011). Personality disorders in later life: Questions about the measurement, course, and impact of disorders. Annual Review of Clinical Psychology, 7, 321349. https://doi.org/10.1146/annurev-clinpsy-090310-120435

Otway, L. J., \& Vignoles, V. L. (2006). Narcissism and childhood recollections: A quantitative test of psychoanalytic predictions. Personality and Social Psychology Bulletin, 32(1), 104-116. https://doi.org/10.1177/0146167205279907

Park, E. (1998). Individualism/collectivism, self-concept, and social behavior: Falseuniqueness and the spiral of silence hypothesis. Unpublished $\mathrm{PhD}$ dissertation, Stanford University, USA.

Paulhus, D. L. (2001). Normal narcissism: Two minimalist accounts. Psychological Inquiry, 12(4), 228-230.

Paulhus D. L., \& Williams, K. M. (2002). The dark triad of personality: Narcissism, Machiavellianism, and Psychopathy. Journal of Research in Personality, 36(6), 556-563. https://doi.org/10.1016/S0092-6566(02)00505-6 
Pendergast, T. (2000) Creating the Modern Man: American Magazines and Consumer Culture: 1900-1950. Columbia, Missouri: University of Missouri Press.

Perenc, L. \& Radochonski, M. (2013) Psychopathic traits and reactive-proactive aggression in a large community sample of Polish adolescents. Child Psychiatry \& Human Development, 45(4), 465-471. https://doi.org/10.1007/s10578-013-0432-4

Persson, B. (2013) Sub-clinical psychopathy and empathy. Unpublished Thesis submitted to achieve the Bachelor Degree in Cognitive Neuroscience. University of Skövde. https://www.diva-portal.org/smash/record.jsf?pid=diva2\%3A646254\&dswid=8129

Persson, B., Kajonius, J.P. \& Garcia, D. (2017) Revisiting the structure of the Dark Triad. Assessment, 26(1) 1-14. https://doi.org/10.1177/1073191117701192

Peterson, G. W., Steinmetz, S. K., \& Wilson, S. M. (2003). Cultural and cross-cultural perspectives on parent-youth relations. Marriage \& Family Review, 35(3/4), 5-19. https://doi.org/10.1300/J002v35n03_02

Piquero, A. R., Farrington, D. P., Fontaine, N. M. G., Vincent, G., Coid, J., \& Ullrich, S. (2012). Childhood risk, offending trajectories, and psychopathy at age 48 years in the Cambridge Study in Delinquent Development. Psychology, Public Policy, and Law, 18(4), 577-598. https://doi.org/10.1037/a0027061

Poless, G. P., Torstveit, L., Luggo, R., Andreassen, M. \& Sütterlin, S. (2017) Guilt and proneness to shame: Unethical behaviour in grandiose and vulnerable narcissism. Europe's Journal of Psychology, 14(1), 28-43. https://doi.org/10.5964/ejop.v14i1.1355

Porter, S., ten Brinke, L., Baker, A., \& Wallace, B. (2011). Would I lie to you? "Leakage" in deceptive facial expressions relates to psychopathy and emotional intelligence. Personality and Individual Differences, 51(2), 133-137. https://doi.org/10.1016/j.paid.2011.03.031

Prado, E. C., Treeby, M. \& Crowe, S. (2016) Examining the relationships between subclinical psychopathic traits with shame, guilt, and externalising response tendencies to everyday transgressions. The Journal of Forensic Psychiatry \& Psychology, 27(4), 569-585. https://doi.org/10.1080/14789949.2016.1167933

Ritchie, T. D., Walker, W. R., Marsh, S., Hart, C., \& Skowronski, J. J. (2015). Narcissism distorts the fading affect bias in autobiographical memory. Applied Cognitive Psychology, 29(1), 104-114. https://doi.org/10.1002/acp.3082

Roberts, D. L. A. \& Coid, W. J. (2007) Psychopathy and offending behaviour: Findings from the national survey of prisoners in England and Wales. Journal of Forensic Psychiatry and Psychology, 18(1), 23-43. https://doi.org/10.1080/14789940601012698

Ronningstam, E. (2005). Identifying and understanding narcissistic personality. Oxford: Oxford University Press. 
Ronningstam, E. (2017) Intersect between self-esteem and regulation in narcissistic personality disorder- implications for alliance building and treatment. Borderline Personality Disorders and Emotion Dysregulation, 4(3), 2-13. https://doi.org/10.1186/s40479-017-0054-8

Rose, P. (2007). Mediators of the association between narcissism and compulsive buying: The roles of materialism and impulse control. Psychology of Addictive Behaviors, 21(4), 576581. https://doi.org/10.1037/0893-164X.21.4.576

Schalkwijk, F. W., Dekker, J., Peen, J. \& Stams, J. (2016) Narcissism, self-esteem, shame regulation and juvenile delinquency. Forensic Science \& Criminology, 1(1). https://doi.org/10.15761/FSC.1000105

Schimmenti, A., Passanisi, A., Pace, U., Manzella, S., Di Carlo, G., \& Caretti, V. (2014). The relationship between attachment and psychopathy: A study with a sample of violent offenders. Current Psychology, 33(3), 256-270. https://doi.org/10.1007/s12144-014-9211-z

Schulze L., Dziobek I., Vater A., Heekeren H.R., Bajbouj M., Renneberg B., Heuser I. \& Roepke S. (2013) Gray matter abnormalities in patients with narcissistic personality disorder. Psychiatry Research, 47(10), 1363-9. https://doi.org/10.1016/j.jpsychires.2013.05.017

Shea, M. T. \& Yen, S. (2003). Stability as a distinction between Axis I and Axis II disorders. Journal of Personality Disorders, $17(5), \quad 373-$ https://doi.org/10.1521/pedi.17.5.373.22973

Skeem, J. L., Poythress, N., Edens, J. F., Lilienfeld, S. O., \& Cale, E. M. (2003). Psychopathic personality or personalities? Exploring potential variants of psychopathy and their implications for risk assessment. Aggression and Violent Behavior, 8(5), 513-546. https://doi.org/10.1016/S1359-1789(02)00098-8

Smolewska, K. \& Dion, L.K. (2005) Narcissism and adult attachment: A multivariate approach. Self and Identity, 4(1), 59-68. https://doi.org/10.1080/13576500444000218

Stewart, K. D., \& Bernhardt, P. C. (2010). Comparing millennials to pre-1987 students and with one another. North American Journal of Psychology, 12(3), 579 - 602.

Stinson, F. S., Dawson, D. A., Goldstein, R. B., Chou, S. P., Huang, B., Smith, S. M., ... Grant, B. F. (2008) Prevalence, correlates, disability and comorbidity of DSM-IV narcissistic personality disorder: Results from wave 2 national epidemiological survey on alcohol and related conditions. Journal of Clinical Psychiatry, 69(7), 1033-45. https://doi.org/10.4088/JCP.v69n0701

Sukholdosky, D., Golub, A. \& Cromwell, E. (2001) Development and validation of the Anger Rumination Scale. Personality and Individual Differences, 31(5), 689-700. https://doi.org/10.1016/S0191-8869(00)00171-9

Triandis, H. C. (1989). The self and social behavior in different cultural contexts. Psychological Review, 96(3), 269-289. https://doi.org/10.1037/0033-295X.96.3.506 
Vernon, P. A., Villani, V. C., Vickers, L. C. \& Harris, J. A. (2008). A behavioral genetic investigation of the Dark Triad and the Big 5. Personality and Individual Differences, 44(2), 445-452. https://doi.org/10.1016/j.paid.2007.09.007

Vignoles, V. L., Chryssochoou, X., \& Breakwell, G. M. (2000). The distinctiveness principle: Identity, meaning, and the bounds of cultural relativity. Personality and Social Psychology Review, 4(4), 337-354. https://doi.org/10.1207/S15327957PSPR0404 4

Vyas, K. (2015) Psychopathic Traits and Everyday Social Behaviour. Unpublished PhD dissertation, University College London, UK.

White, A.B. (2014) Who cares when nobody is watching? Psychopathic traits and empathy in prosocial behaviors. Personality and Individual Differences, 56, 116-121. https://doi.org/10.1016/j.paid.2013.08.033

Widiger, T. A., \& Lynam, D. R. (1998). Psychopathy as a variant of common personality traits: Implications for diagnosis, etiology, and pathology. In T. Millon (Ed.), Psychopathy: Antisocial. criminal, and violent behavior (pp. 171-187). New York: Guilford Press.

Williams, K. M., \& Paulhus, D. L. (2004). Factor structure of the Self-Report Psychopathy scale (SRP II) in nonforensic samples. Personality and Individual Differences, 37, 765-778. https://doi.org/10.1016/j.paid.2003.11.004

Wink, P. M. (1991). Two faces of narcissism. Journal of Personality and Social Psychology, 61(4), 590-597. https://doi.org/10.1037/0022-3514.61.4.590

Woodmass, K., \& O'Connor, B. P. (2018). What is the opposite of psychopathy? A statistical and graphical exploration of the psychopathy continuum. Personality and Individual Differences, 131, 254-260. https://doi.org/10.1016/j.paid.2018.05.004

Youli, H. \& Chang, L. (2015) A comparative study between the dark personality and the Big Five. Canadian Social Science, 11(1), 93-98. https://doi.org/10.3968/5715

Young, J. E. (1999) Practitioner's resource series. Cognitive therapy for personality disorders: A schema-focused approach (3rd ed.). Sarasota, FL: Professional Resource Press/Professional Resource Exchange.

Yu, A. (1996). Ultimate life concerns, self and Chinese achievement motivation. In M. Bond (Ed.), The handbook of Chinese psychology (pp. 227-246). Hong Kong: Oxford Press. 


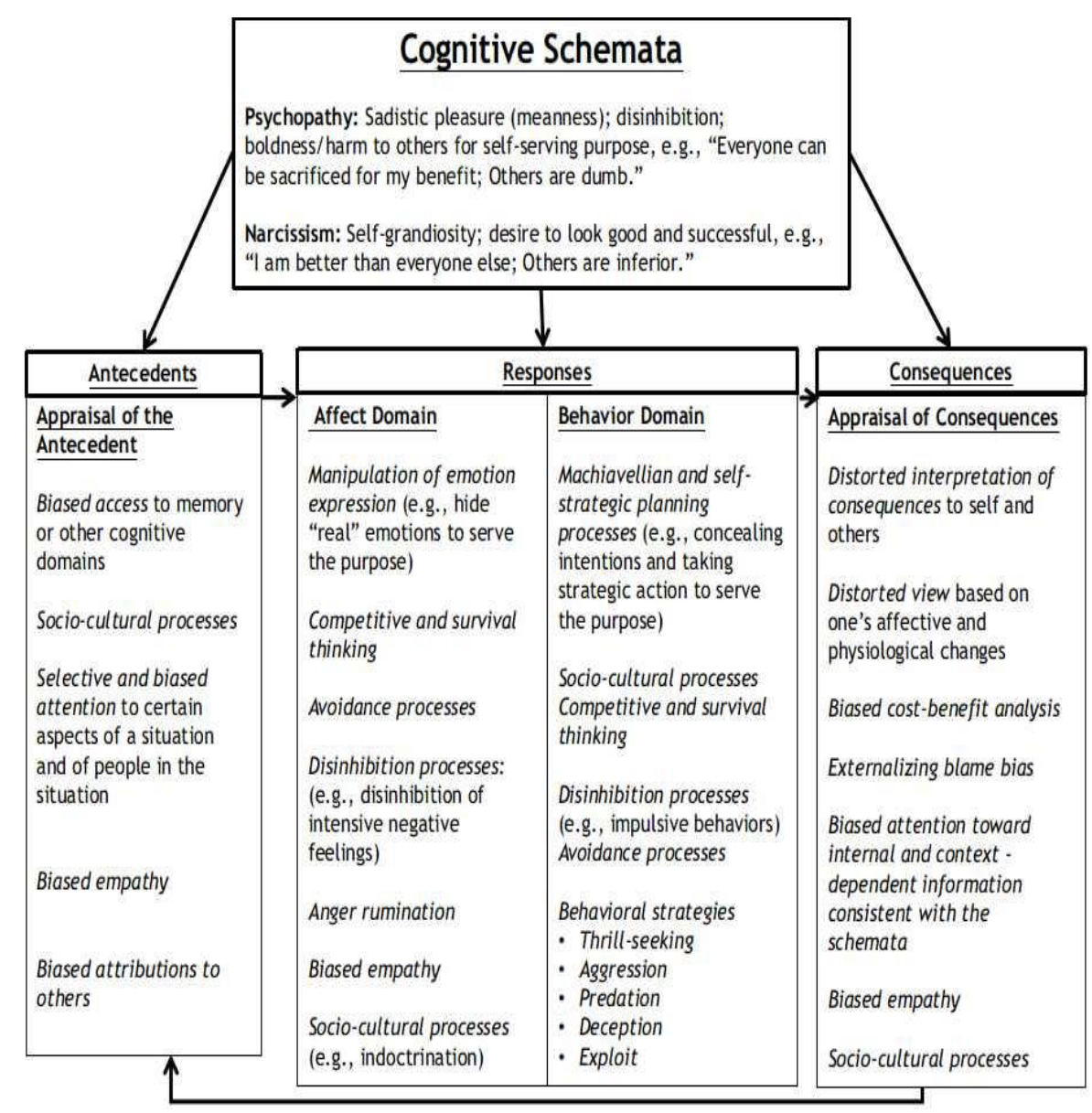

Figure 1. SCIPNP: Cognitive Schemata and Appraisal and Socio-Cultural Processes associated with each Cognitive Stage of Information-Processing of an Event 


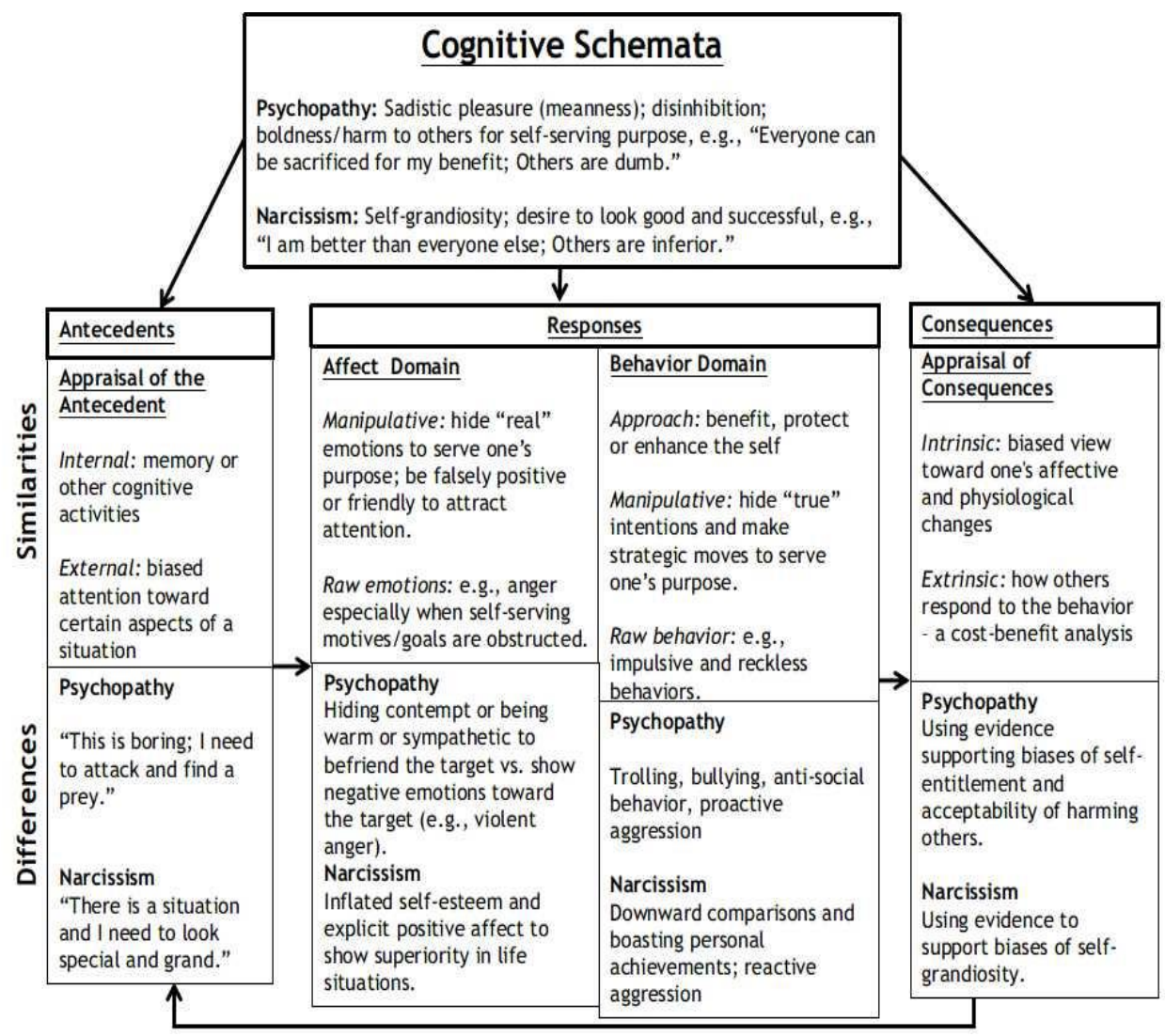

Figure 2. SCIPNP: Narcissistic and Psychopathic Cognitive Schemata and their similarities and differences in appraisals, affect and behavior 